Research Article

\title{
Lightness contrast \& assimilation: testing the hypotheses
}

\author{
Predrag Nedimović ${ }^{\varpi 1}$ (D), Sunčica Zdravković ${ }^{2}$ \\ 1 Laboratory of Experimental Psychology, Department of Psychology, Faculty of \\ Philosophy, University of Belgrade, Serbia \\ ${ }^{2}$ Laboratory of Experimental Psychology, Department of Psychology, Faculty of \\ Philosophy, University of Novi Sad, Serbia
}

\section{ABSTRACT}

In lightness contrast, a target will alter its lightness to decrease similarity with neighbouring surfaces, while in lightness assimilation similarity is increased. Previous studies emphasized some aspects of the stimulation pattern that seem to favour the occurrence of one or both of these two phenomena: spatial frequency of the inducers, magnitude and direction of the reflectance difference between the target and the inducers. More importantly, based on previous studies three precise hypotheses can be formulated that predict the occurrence of the two phenomena: spatial frequency, differential stimulation, and assimilation asymmetry. We manipulated target and inducers' reflectance and inducers' spatial frequency. This enabled us to both tests the importance of these factors, and to predict lightness for each stimulus, according to all three hypotheses. Our results confirmed the influence of the tested factors on target lightness. The proposed hypotheses were poor in predicting the obtained data. The differential stimulation hypothesis correctly predicted the obtained effect in less than half our stimuli. The spatial frequency hypothesis did not correctly predict the strength of obtained effects, as we obtained the largest assimilation effects with low spatial frequency inducers. Finally, the assimilation asymmetry hypothesis did not predict a single obtained effect. 
Contrary to this hypothesis prediction, we obtained contrast with decrement and assimilation with increment inducers.

Keywords: lightness, contrast, assimilation, spatial frequency, differential stimulation hypothesis

UDK: 159.9.072

DOI: 10.19090/pp.2021.3.253-

275

Received: 23.03.2021.

Revised: 10.06.2021.

Accepted: 11.06.2021.

Copyright (c) 2021 The Author(s).

This is an open access article distributed under the terms of the Creative Commons Attribution License, which permits unrestricted use, distribution, and reproduction in any medium, provided the original author and source are credited.

${ }^{凶}$ Corresponding author e-mail: predrag.nedimovic@f.bg.ac.rs 


\section{Introduction}

The lightness of an object heavily depends on its context, hence physically identical targets presented in different contexts can have very different appearances. Two prominent phenomena illustrate this point very well: lightness contrast and assimilation. In lightness contrast, a target embedded among other surfaces will alter its lightness to decrease similarity with those other surfaces (i.e., inducers, Figure 1A). On the contrary, in lightness assimilation, the lightness of a target is altered in a way that similarity with the inducers is increased (Figure 1B). So not only do these two phenomena demonstrate this alternation of the target appearance due to their immediate surrounding, but this perceptual change may go in opposite directions.

The two classical displays that are used to produce contrast and assimilation contain important differences (Figure $1 \mathrm{~A}$ and $1 \mathrm{~B}$, respectively). The configuration of the inducers is different: in the contrast display, inducers are perceived as two "frames", while in the assimilation display, inducers are perceived as "stripes". Another important difference is that there is a significant disparity in the physical area that the inducers occupy: their area is much larger in the classical contrast display. However, the classical contrast display can be modified in a way that inducers now occupy the same area as those in assimilation display, and are perceived as "stripes" (Figure 1C).

The most notable difference between those two classical displays is phenomenological. In the classical contrast display (Figure 1A), the grey targets are perceived as figures, while in the classical assimilation display (Figure 1B), the inducers are those objects perceived as figures. This difference can be mitigated by manipulating the distance between the targets and the inducers (Figure $\mathrm{IE}$ and $\mathrm{TF}$ ), resulting in both targets being backgrounds. Segregating the target and the inducers in depth by presenting inducers $30 \mathrm{~cm}$ in front of the targets achieves three things: 1) grey squares that represent the targets are now perceived as backgrounds, 2) inducers are perceived as figures, and 3) targets and inducers occupy an equal area of the displays. In these variations, however, the effects of the 
contrast (Figure 1E) and the assimilation (Figure 1F) might be weakened or reversed (Soranzo et al., 2010; Soranzo et al., 2020).

Numerous studies were conducted to test the precise stimuli conditions that would give rise to either contrast or assimilation.

In a series of experiments, Helson (Helson \& Rholes, 1959; Helson \& Joy, 1962), varied the spatial frequency and width of the inducers. Results showed that densely distributed $(.3 \mathrm{~cm}$ interval) but thin $(.3 \mathrm{~cm})$ inducers produced an assimilation effect. Sparsely distributed (1 $\mathrm{cm}$ interval) but thick $(1 \mathrm{~cm})$ inducers produced a contrast effect. Medium levels of inducers' spatial frequency and width produced a veridical perception of the target, i.e. closer to its reflectance value. In more simple terms, these results indicate that high spatial frequency inducers should produce assimilation, and low spatial frequency inducers should produce contrast. We refer to this prediction as to the spatial frequency hypothesis.

Figure 1

Lightness contrast and assimilation displays

contrast assimilation

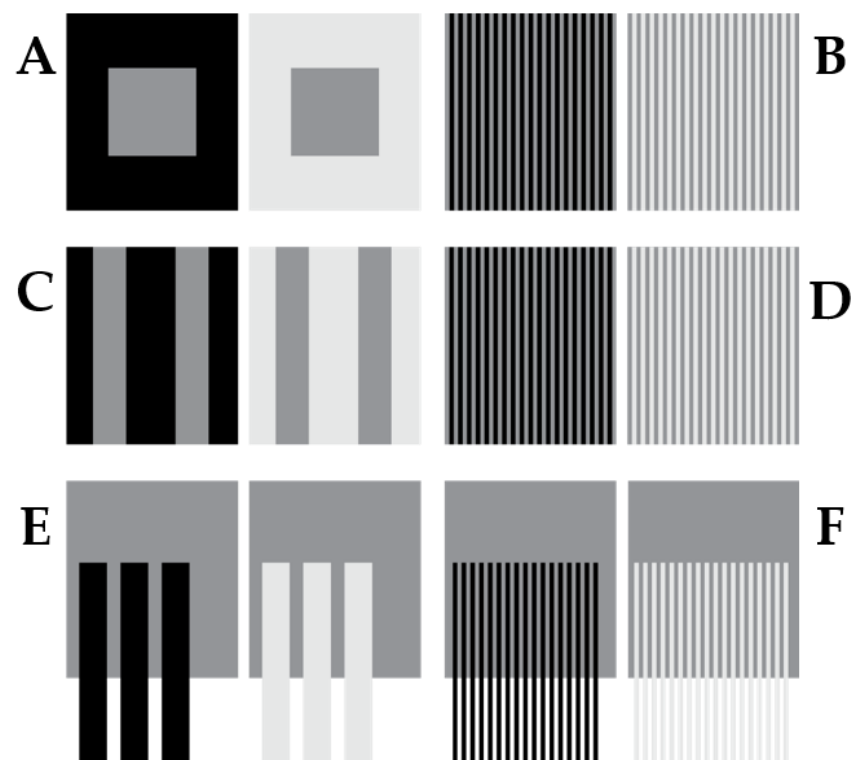


Steger (1968) investigated the effects of reflectance difference between the target reflectance $\left(T_{R}\right)$ and the inducers reflectance $\left(I_{R}\right)$. Results showed that the small reflectance difference $\left(T_{R}-I_{R} \approx|8 \%|\right)$ produced lightness assimilation, while the large difference $\left(T_{R}-I_{R} \approx|28 \%|\right)$ produced lightness contrast. Medium reflectance differences produced veridical perception. To explain these results, the Differential stimulation hypothesis was formulated. Small reflectance difference produced similar photoreceptor activation levels, resulting in weak inhibition levels, and thus giving rise to the assimilation effect, while large reflectance difference produces various photoreceptor activation levels that produce strong inhibition levels, giving rise to the contrast effect.

More recently, Soranzo and colleagues (2010) further scrutinized the effect of high spatial frequency inducers on assimilation, combining this effect with manipulation of luminance. They varied inducer luminance while controlling for spatial frequency (high) and reflectance difference between the target and the inducers. Results showed that both dark and light inducers can produce an assimilation effect.

However, not all of the results supported the differential stimulation hypothesis. Beck (1966) controlled inducer spatial frequency $(.3 \mathrm{~cm}$ interval) and width $(.3 \mathrm{~cm})$, and also controlled target reflectance $\left(T_{R}=20 \%\right)$, while varying the inducers' reflectance. Results showed that inducers with the $10 \%$ reflectance produced an assimilation effect. On the other hand, inducers with the $20 \%$ reflectance produced a contrast effect, meaning that equal reflectance difference $\left(T_{R}-I_{R}=|10 \%|\right)$ can produce both contrast and assimilation effects. In this research, it was the direction of the reflectance difference that predicted the two effects: decrement inducers $\left(I_{R}<T_{R}\right)$ produced assimilation effects, while increment inducers $\left(I_{R}>T_{R}\right)$ produced contrast effects. These results showed that only decrement inducers should produce assimilation. We refer to this prediction as to the assimilation asymmetry hypothesis.

Similar results were later obtained by de Weert \& Spillmann (1994), with more complex stimuli (pincushion formed by four arcs). Both black and white arcs influenced the pincushion area to appear darker, meaning that black arcs produced assimilation, and white arcs produced contrast. 
Soranzo et. al (2020) varied spatial frequency (low and high) and inducers reflectance $(4.6 \%$ and $90 \%$ ) while controlling for target reflectance (25.6\%). Results showed that low spatial frequency conditions produced contrast effects. In the high spatial frequency conditions, dark inducers produced assimilation, while light inducers produced contrast. These results support the assimilation asymmetry hypothesis.

These studies are inconclusive for the stimulus configurations that give rise to lightness contrast vs. assimilation. One group of authors stressed the importance of the magnitude of the reflectance difference (Helson, Steger), while others stressed the importance of the direction of the reflectance difference (Beck, de Weert).

Thus, this important question of stimuli conditions remains largely unanswered and therefore it is essential to emphasize that the direct comparison of the presented findings and consequently their conclusions might be misleading. In our opinion, such comparison is problematic as there were some major stimuli and procedural differences that prevent such comparisons and cast doubt on conclusions. Festinger (1970) showed that a variety of such differences influence results (Table 1): visual angle, number of targets, number of inducers or repetitions, exposure duration, and task type (for example, Helson used comparison technique, Soranzo used Munsell scale). However, none of the authors limited their conclusions to coplanar conditions, so we introduced the distance between the target and the inducers as it allowed us to achieve the desired methodology. 


\section{Table 1}

Stimuli dimensions \& procedure in previous studies

\begin{tabular}{lccccccc}
\hline & \multicolumn{2}{c}{ Target } & \multicolumn{2}{c}{ Inducers } & \multicolumn{3}{c}{ Procedure } \\
\cline { 2 - 7 } & Dim. $(\mathrm{cm})$ & V.A. $\left(^{\circ}\right)$ & Dim. $(\mathrm{cm})$ & V.A. $\left({ }^{\circ}\right)$ & Dis. $(\mathrm{cm})$ & Exp. $(\mathrm{sec})$ & Rep. \\
\hline Helson & $18 \times 30$ & $3.44 \times 5.72$ & $18 \times 0.3$ & $3.44 \times 0.06$ & 300 & 3 & 4 \\
Streger & $18 \times 30$ & $3.44 \times 5.72$ & $18 \times 0.3$ & $3.44 \times 0.06$ & 300 & 2 & 4 \\
Beck & $5 \times 5$ & $1.72 \times 1.72$ & $5 \times 0.3$ & $1.72 \times 0.19$ & 167 & 3 & 4 \\
de Weert & $6 \times 6$ & $.687 \times .687$ & $0.5 \times 0.5$ & $0.06 \times 0.06$ & 500 & $n / a$ & $n / a$ \\
Soranzo & $\mathrm{n} / \mathrm{a}$ & $10.2 \times 10.2$ & $\mathrm{n} / \mathrm{a}$ & $0.95 \times 0.2$ & $\mathrm{n} / \mathrm{a}$ & $\mathrm{n} / \mathrm{a}$ & 4 \\
$(2010)$ & & & & & & & \\
Soranzo & $10.3 \times 10.3$ & $3.93 \times 3.93$ & $1.2 \times 0.3$ & $0.46 \times 0.11$ & 150 & $\mathrm{n} / \mathrm{a}$ & $\mathrm{n} / \mathrm{a}$ \\
$(2020)$ & & & & & & \\
\hline
\end{tabular}

Notes: Dim. - dimensions, V.A.- visual angle, Dis. - distance, Exp. - exposition, Rep. repetition

Given the described experimental variations, we put together an experiment that simultaneously manipulates the following 3 factors: Target reflectance, Inducer reflectance, and Inducer spatial frequency. The factors we have chosen were those that a) have been shown to produce both contrast and assimilation, and b) can test the proposed hypotheses. These 3 factors enabled us to construct 18 test stimuli so that for each one of them we could deduce a precise prediction from the previous literature, i.e. from each of the hypotheses. In addition, we used the stimuli that provided the most methodological clarity, discarding all other differences while producing both contrast and assimilation (Figure 2).

\section{Method}

\section{Participants}

9 first-year Psychology students (8 female, $M_{\text {age }}=21.1$ ) took part in all experimental sessions to fulfill the class requirements. All participants, according to their self-report, had a normal (or corrected-to-normal) vision. Since this was lightness experiment colour-blindness was not tested. Each 
participant, after the procedure was explained, signed a written consent agreeing to participate in the experiment and they were treated under the Declaration of Helsinki.

The number of participants was predetermined using G*Power analysis. It showed that for the power of 0.867 (Repeated measures, within factors; $f(U)=.874 ; \beta / \alpha$ ratio $=1$; no. of groups $=1$; no. of measurements $=2$ ) we need 9 participants (the effect size was determined by results obtained in Soranzo et al, 2020).

Figure 2

Illustration of 3-factor variations on test stimuli, with inducers "placed in front" of the target

target reflectance

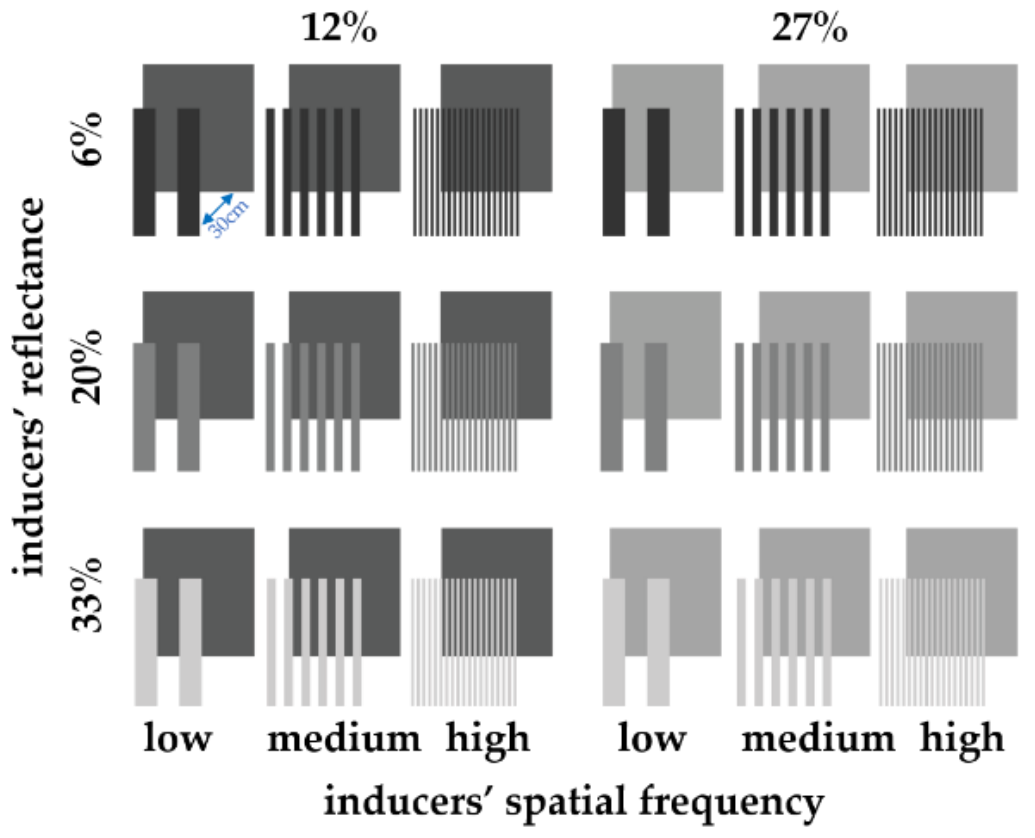




\section{Stimuli}

20 stimuli were used in this study (18 test stimuli with the inducers as in Figure 2, and 2 controls without any inducers). All stimuli varied in target reflectance ( $12 \%$ \& 27\%, that is 4 and 5.75 Munsell paper, or 16.16 and 28.33 $\mathrm{cd} / \mathrm{m}^{2}$ ). Stimuli with the inducers (vertical stripes $30 \mathrm{~cm}$ in front of the targets) also varied in inducers' reflectance $(6 \%, 19 \%$, and $33 \%$, i.e. 3,5 , and 6.25 Munsell and 6.26, 19.51 and $37.92 \mathrm{~cd} / \mathrm{m}^{2}$, respectively) and inducers' spatial frequency (width and interval $.2 \mathrm{~cm}, .6 \mathrm{~cm}$, and $1.56 \mathrm{~cm}$ ). Stimuli and described variations are specified in Table 2.

\section{Table 2}

Target and inducers dimensions

\begin{tabular}{lccccccccc}
\hline & \multirow{2}{*}{ TARGET } & \multicolumn{7}{c}{ INDUCER (one) } \\
\cline { 4 - 9 } & & & \multicolumn{2}{c}{ high s.f. } & medium s.f. & low s.f. \\
\hline & height & width & height & width & height & width & height & width \\
\hline dimensions $(\mathrm{cm})$ & 7.20 & 6.24 & 7.20 & 0.16 & 7.20 & 0.48 & 7.20 & 1.25 \\
visual angle $\left(^{\circ}\right)$ & 3.44 & 2.98 & 3.44 & 0.08 & 3.44 & 0.23 & 3.44 & 0.60 \\
\hline
\end{tabular}

Laboratory set-up

Experiments were conducted in a viewing chamber $(150 \times 75 \times 75 \mathrm{~cm}$, painted black $3 \%$ reflectance, $2.24 \mathrm{~cd} / \mathrm{m}^{2}$ ) placed in a dark room. This specially designed chamber allowed for precise control of illumination intensity. There was a single illumination source in the chamber $(220 \mathrm{~V}, 60 \mathrm{~W})$, placed $10 \mathrm{~cm}$ above the space designed for the participant's head. The target $\left(3.44^{\circ} \times 2.98^{\circ}\right)$ was positioned on the opposite chamber wall, $150 \mathrm{~cm}$ away from the observer. A black stand was placed on the chamber floor (120 $\mathrm{cm}$ away from the observer), that was used to present inducers. This manipulation was introduced to avoid confusion about whether the target is a figure or a ground. In this procedure, the targets were always in the same position. 
The Munsell scale was also on the chamber floor, sited under its own illumination and on the white background. It had 16 grey shades spanning the full range from black to white, in equidistant steps (reflectance 3-90\%).

\section{Procedure}

The experimental sessions were run individually. After the practice trials, each of the 20 stimuli was presented two times in the randomized order. A stimulus was presented for 3 seconds, after which the experimenter would remove it from the participant's view, to control for stimuli exposure time. This manipulation was introduced after Festinger et al. (1970) showed that this factor can influence contrast and assimilation. The task was to produce lightness matches using the Munsell scale.

Hypotheses predictions

The main goal of this study was to test the hypotheses proposed in the literature. The predictions for the first two hypotheses are presented in Figure 3, while the predictions from the $3^{\text {rd }}$ hypothesis are presented in Figure 4.

Based on the differential stimulation hypothesis, lightness assimilation is expected in conditions where $T_{R}-I_{R}=|6 \%|$, while lightness contrast is expected in conditions where $T_{R}-I_{R}=|21 \%|$. The Spatial frequency hypothesis predicts that assimilation effects should be stronger when the spatial frequency is high, while contrast effects should be stronger when the spatial frequency is low.

The left section of Figure 3 depicts the combined predictions of these two hypotheses for stimuli with $12 \%$ target reflectance. The yellow dotted line represents veridical lightness for control stimuli (without the inducers) with $12 \%$ target reflectance. Stimuli with $6 \%$ inducers reflectance should produce an assimilation effect (indicated by green markers), making the target appear darker than control stimuli. The largest assimilation effect is expected for the stimulus with high spatial frequency inducers. Stimuli with $12 \%$ inducers reflectance should also produce an assimilation effect (because $\left.T_{R}-I_{R}=|6 \%|\right)$, but they should influence the target to appear 
lighter than control stimuli. Again, the largest assimilation effect is expected for the stimulus with high spatial frequency inducers. Stimuli with $33 \%$ inducers reflectance should produce a contrast effect (red markers), influencing the target to appear darker than the control stimuli. Under these conditions, it is expected that the largest contrast effect should be obtained by the stimulus with the low spatial frequency inducers.

The Right section of Figure 3 depicts these two hypotheses' predictions for stimuli with $27 \%$ target reflectance. The blue dotted line represents veridical lightness for control stimuli (without the inducers) with $27 \%$ target reflectance. The most notable difference between the two sections of Figure 3 is that the prediction for every stimulus in the right section $\left(T_{R}=27 \%\right)$ is higher in lightness when compared to stimuli on the left section $\left(T_{R}=12 \%\right)$ due to the physically lighter target. Another difference between these two sections is that in the conditions where $T_{R}=27 \%$, stimuli with $6 \%$ and $33 \%$ inducers reflectance are now expected to produce opposite effects (then in conditions where $T_{R}=12 \%$ ) as depicted with green and red dots changed positions on the white and black line. Finally, for the inducers of $20 \%$ reflectance, the tilt is changed but in fact, it represents the expectation that, in both cases, the decrease of spatial frequency would lead to values closer to baseline.

\section{Figure 3}

Differential stimulation and spatial frequency hypotheses predictions

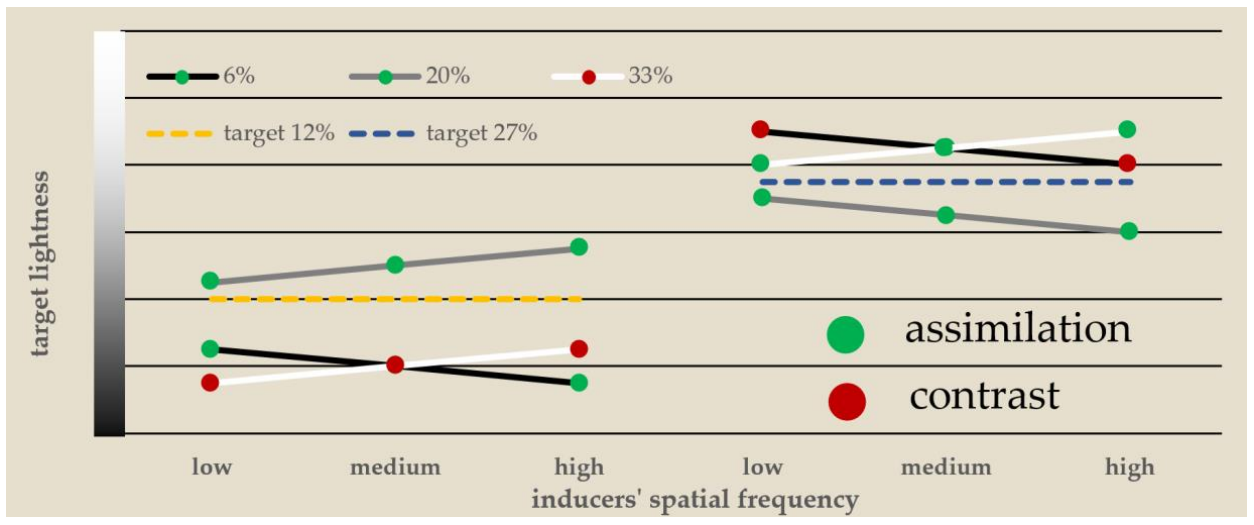


The Assimilation asymmetry hypothesis predicts that decrement inducers will always produce assimilation, while increment inducers will always produce contrast. These predictions are, when applied to our stimuli, as presented in Figure 4.

\section{Figure 4}

\section{Assimilation asymmetry hypothesis}

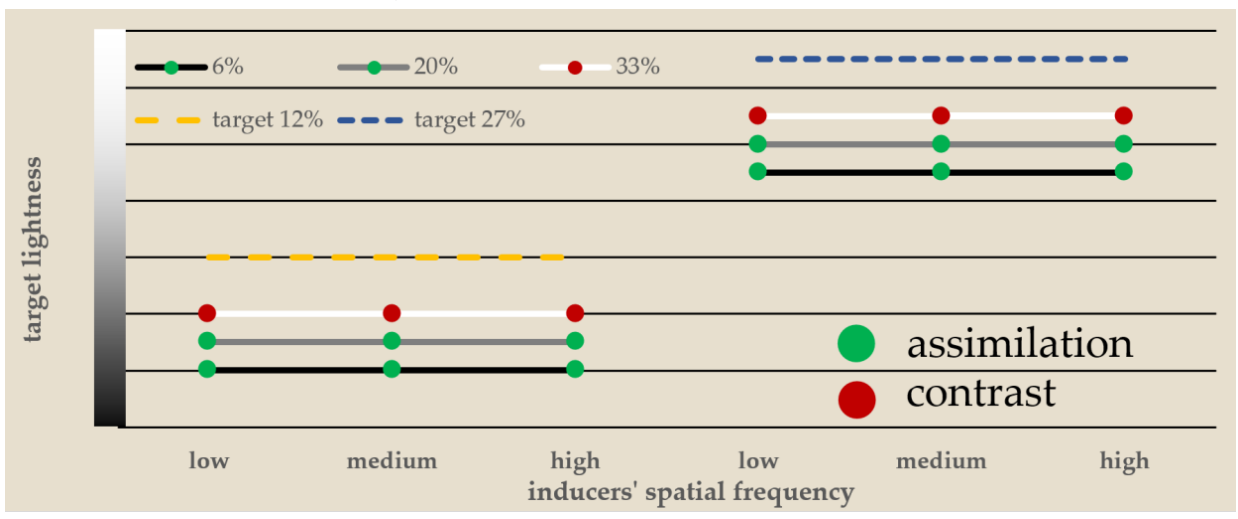

\section{Results}

Three-way ANOVA for repeated measures revealed that three-way interaction was not significant (Table 3), and neither were the 3 two-way interactions (however, the interaction between the reflectance of inducers and the inducers spatial frequency almost reached significance). All three main effects were significant. 
Table 3

Three-way ANOVA for repeated measures results

\begin{tabular}{lcccc}
\hline & $\mathrm{df}$ & $\mathrm{F}$ & $\mathrm{p}$ & part. $\eta^{2}$ \\
\hline target reflectance $\left(\mathrm{T}_{\mathrm{R}}\right)$ & 1,8 & 193.77 & .001 & .96 \\
inducers' reflectance $\left(\mathrm{I}_{\mathrm{R}}\right)$ & 2,16 & 8.46 & .01 & .51 \\
inducers spatial frequency $\left(\mathrm{I}_{\mathrm{S} F}\right)$ & 2,16 & 6.44 & .01 & .45 \\
\hline $\mathrm{T}_{\mathrm{R}} \times \mathrm{I}_{\mathrm{R}}$ & 2,16 & 0.62 & .55 & .07 \\
$\mathrm{~T}_{\mathrm{R}} \times \mathrm{I}_{\mathrm{SF}}$ & 2,16 & 0.41 & .67 & .05 \\
$\mathrm{I}_{\mathrm{R}} \times \mathrm{I}_{\mathrm{SF}}$ & 4,32 & 2.48 & .06 & .24 \\
\hdashline $\mathrm{T}_{\mathrm{R}} \times \mathrm{I}_{\mathrm{R}} \times \mathrm{I}_{\mathrm{SF}}$ & 4,32 & 0.89 & .48 & .10 \\
\hline
\end{tabular}

Results showed a main effect of target reflectance. This is a standard effect and it simply shows that targets with higher (27\%) reflectance were judged as having higher lightness than targets with lower (12\%) reflectance (Figure 5, left vs. right side of the graph). More interestingly the main effect of inducer reflectance was also significant (Figure 5, white vs. grey vs. black lines). Stimuli with the $20 \%$ reflectance inducers were judged as having lower lightness than those with $6 \%(F(1,8)=16.47, p=.01)$ and $33 \%$ reflectance inducers $(F(1,8)=8.17, p=.02)$. There was no difference in lightness between stimuli with $6 \%$ and $33 \%$ reflectance inducers $(F(1,8)=0.71, p=.42)$. The main effect of spatial frequency was also significant (Figure 5, 3 levels presented on the $x$-axis). Stimuli with high spatial frequency inducers were perceived as having lower lightness than the stimuli with medium $(F(1,8)=13.01, p=.01)$ and low spatial frequency inducers $(F(1,8)=7.95, p=.02)$. There was no difference in lightness between stimuli with medium and low spatial frequency inducers $(F(1,8)=0.26, p=.63)$. 


\section{Figure 5}

Results in the conditions with $T R=12 \%$ (left) and $T R=27 \%$ (right)

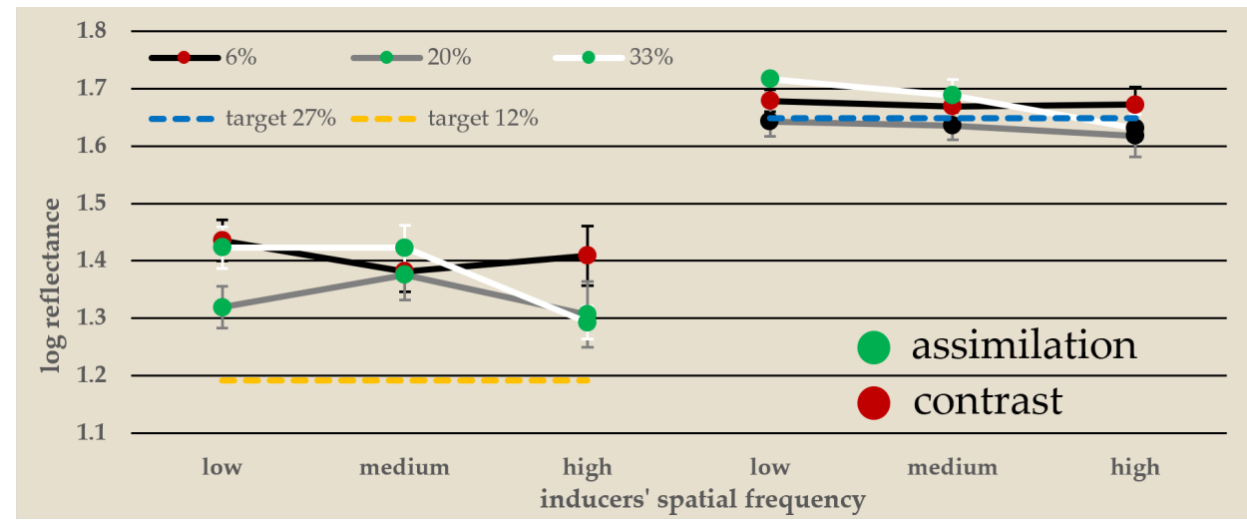

Notes. Dashed lines are results for the control condition (i.e., targets without inducers). Green markers indicate assimilation, red markers indicate contrast, black markers indicate unaltered lightness of the target (it was the same as in the control condition).

Although these results informed us about the contribution of each factor manipulated in the experiment, a more detailed analysis was performed to test the effectiveness of hypotheses predictions.

\section{Hypotheses testing}

Figure 5 contains contrast/assimilation assignment for each data point obtained in our experiment. Comparing the target lightness of the test and the control stimuli allowed us to analyse the direction of the effect that test stimuli produced. Take, for example, data points on the left side of the graph (target 12\%), for low frequency, for the white and black line. One of them is green for assimilation, and another is red for contrast. Both matches appeared lighter than the observed target reflectance (obtained from the control stimuli and presented with the dashed line) but the one with the dark inducers (black line) produced contrast (red marker) while the one with the light inducers produced assimilation (green marker).

The differential stimulation hypothesis predicts that an assimilation effect should occur in conditions in which the reflectance difference between targets and inducers is small and that a contrast effect should 
occur when this difference is large. The spatial frequency hypothesis predicts the largest assimilation effects when inducers have high spatial frequency, and that the largest contrast effect should be produced with low spatial frequency stimuli (Figure 3).

The predictions of these two hypotheses were first tested for conditions where $T_{R}=12 \%$ (Figures $3 \& 5$, left section). Stimuli with $I_{R}=20 \%$ produced an assimilation effect. This effect is in accordance with the differential stimulation hypothesis predictions. However, the spatial frequency effect was not significant $(F(2,16)=0.95, p=.41)$. Stimuli with $I_{R}=$ $6 \%$ produced contrast effects. This effect is opposite to differential stimulation hypothesis predictions. Spatial frequency effect was not significant $(F(2,16)=0.74, p=.49)$. Stimuli with $I_{R}=33 \%$ produced assimilation effects, contrary to differential stimulation hypothesis prediction. Spatial frequency effect was significant $(F(2,16)=5.42, p=.02)$. Stimuli with high spatial frequency inducers produced a weaker assimilation effect than stimuli with medium $(F(1,8)=9.42, p=.01)$ and $\operatorname{low}(F(1,8)=15.75, p=.01)$ spatial frequency inducers.

The predictions of these two hypotheses were then tested for conditions in which $T_{R}=27 \%$ (Figures $3 \& 5$, right section). Stimuli with $I_{R}=$ $33 \%$ produced one null and two assimilation effects. The effect of Spatial frequency was significant $(F(2,16)=8.10, p=.01)$. The stimulus with the high spatial frequency produced a null effect (opposite to differential stimulation hypothesis), while medium $(F(1,8)=7.76, p=.02)$ and low $(F(1,8)=13.93, p=$ .01) spatial frequency stimuli produced assimilation effects. Stimuli with $I_{R}=$ $20 \%$ produced null effects, and the effect of spatial frequency was not significant $(F(2,16)=0.28, p=.76)$. Stimuli with $I_{R}=6 \%$ produced the expected contrast effects. The effect of spatial frequency was not significant $(F(2,16)=0.08, p=.92)$.

The predictions of assimilation asymmetry can be evaluated by examining Figures $4 \& 5$. In the conditions where $T_{R}=12 \%$ decrement inducers produced contrast, while increment inducers produced assimilation. These results contradict assimilation asymmetry hypothesis predictions. 
In the conditions where $T_{R}=27 \%$ decrement inducers again produced contrast, while increment inducers $\left(l_{R}=33 \%\right)$ produced assimilation effect in two conditions.

\section{Discussion}

The lightness of an object can be altered in several ways. One of these ways - by changing the reflectance of neighbouring surfaces - is extremely counterintuitive. This phenomenon is well documented in the classical literature (Katz, 1935) as well as in the lightness theories (Bresssan, 2006; Gilchrist et al 1999). The number of adjacent surfaces is important, with a single surface producing the most aberrant results (Agostini \& Galmonte, 1999) and the increased number of surfaces producing more veridical perception (Gilchrist \& Annan, 2002). Furthermore, the spatial layout of these surfaces is highly relevant (Logvinenko et al., 2008; Todorović \& Zdravković, 2014). Two such renowned stimuli configurations present a puzzle for lightness researchers for decades and, still, we do not have a universally accepted explanation for them. Those are lightness contrast and lightness assimilation. Each of the two has a standard layout (Figure $1 \mathrm{~A}$ and 1B) that has been thoroughly explored (Agostini, \& Galmonte, 2002; Bressan, \& Actis-Grosso, 2006; Jameson, \& Hurvich, 1975).

In this study we investigated contrast and assimilation simultaneously since it has been debated that not only, they produce perceptually exactly opposite effects, suggesting that they are endpoints of the same continuum, but may even rely on a common mechanism (Helson, 1963; Steger, 1969). Namely, on the lightness contrast display (Figure 1A), the lightness of a target is altered in the opposite direction to the reflectance of the neighbouring regions, i.e. inducers, on the assimilation display (Figure 1B), lightness of a target is altered in the direction that is consistent with the reflectance of the inducers. Previous studies tested various stimuli conditions to understand which factors favour the occurrence of these two effects demonstrating that lightness contrast and assimilation were influenced by the inducers' spatial frequency, and by magnitude and direction of the reflectance difference between the target and the inducers (Spehar et al. 1995). We reasoned that if the two phenomena are the two 
extremes of the same mechanism, they can be generated by a unique display. We produced such a display that allowed us to elicit both contrast and assimilation while varying only those three relevant factors. Finally, to make the two displays even phenomenologically equal, our inducers were placed $30 \mathrm{~cm}$ in front of the target, avoiding the confusion whether the target is a figure or a ground (de Weert, \& van Kruysbergen, 1997). This allowed us to manipulate the inducers while keeping the target and other factors constant, which in our opinion left us with the methodologically cleanest possible scenario. This decision came with some theoretical and methodological caveats that will be discussed shortly.

Our results confirmed the importance of the three factors under examination: target reflectance, inducers' reflectance, and inducers' spatial frequency. We found no interactions among them, suggesting that each manipulation had an additive effect, which was surprising given the previous literature (Helson, 1959; Steger, 1969). The absence of an interaction between target reflectance and inducer reflectance was especially interesting, as this interaction inspired the two proposed hypotheses (Beck, 1966; Helson, 1963). The only interaction that was close to reaching significance was between the inducers' reflectance and spatial frequency, a relationship not mentioned by classical authors.

The main objective of the current study was to test the effectiveness of the hypotheses previously stated in the lightness literature. Based on those hypotheses, for each of our experimental conditions, we could predict whether contrast or assimilation was to be expected. The three hypotheses were not successful in predicting the obtained data. The differential stimulation hypothesis (Steger, 1968) correctly predicted the obtained effects in 8 out of 18 conditions. The expected assimilation effect was obtained in 5 out of 12 conditions, while the expected contrast effect was obtained in 3 out of 6 conditions. The Spatial frequency hypothesis (Helson \& Rholes, 1959) was poor in predicting the magnitude of the obtained effects. The spatial frequency effect was significant in only 6 (out of 18) conditions. The magnitudes of the obtained effects were contrary to the hypothesis predictions: stimuli with inducers reflectance of $33 \%$ produced the strongest assimilation effects when the spatial frequency was low, and 
the smallest effects when the spatial frequency was high. Assimilation asymmetry (Beck, 1966) was strikingly poor in predicting our data: it did not correctly predict a single obtained effect. However, our results showed that an asymmetry was obtained, but the direction of this effect was opposite to what was an expected based on previous study: decrement inducers produced contrast, while increment inducers produce assimilation effects.

We assume that the poor predictive power of the three hypotheses is caused by the same display characteristics that also led to the lack of statistically significant interactions (Table 3), and that is the depth separation between the targets and the inducers. It should be emphasised again that the three hypotheses were originally formulated based on classical studies where there was no distance between the target and the inducers. But also, none of those studies or authors ever specified that coplanarity was among numerous crucial conditions to achieve assimilation or contrast. Contemporary studies on lightness contrast and assimilation (Economou et al., 2015; Soranzo et al., 2010; Soranzo et al., 2020) may provide insight into the absence of interaction between the tested factors.

Soranzo et al. (2020) varied depth (distance between the target and the inducers), stimuli configuration ("contrast-eliciting" and "assimilationeliciting"), and colour of the inducers (white and black). Their results showed an interaction between stimulus configuration and colour of the inducers in the coplanar conditions. However, this interaction was not significant in non-coplanar conditions, indicating that depth influences contrast and assimilation in a non-trivial fashion. That is in Soranzo et al. (2020) depth would even inverse effects of assimilation into contrast. In fact, our conditions, with the inducers placed in front of the targets, should always lead to contrast, according to Soranzo et al. $(2010,2020)$ and King (1988). We did not obtain such results.

Working only on the contrast side of the phenomena, Economou et al. (2015) also showed the influence of depth on lightness: the strength of the reverse contrast illusion dramatically decreases, when compared to coplanar display, in the conditions where the inducers (i.e. "flankers") were perceived to be in front of the targets and the backgrounds (see their figure 
8, second row). This condition resembles our experiment since in both studies inducers were placed in front of the target.

Previously, Gilchrist (1980) offered a theoretical account of the depth effect, by introducing the coplanar ratio principle. According to this principle, the lightness of a surface will be affected mainly by the surfaces that appear to belong to the same plane and not by other surfaces that are placed in different planes even if retinally they are closer together. Clearly, in our experiment, the inducers were seen correctly, i.e. in front of the targets. Coplanar ratio principle predicts that in these conditions, inducers should have less of an effect on the target, than if both inducers and the target are perceived to belong to the same depth plane. Nevertheless, our targets were influenced by our inducers as their lightness was changing when the inducers were present (in comparison to control stimuli), even though they were visibly in the deeper plane. The only difference, in comparison to classical studies, was the decreased intensity of the measured effect which is in agreement with more recent accounts (Economou et al. 2015; Soranzo et al., 2020).

Finally, we turned to the general model of lightness, which was not made to explain assimilation and contrast nor even describes these two effects as part of the same continuum (Gilchrist et al, 1999). The main reason to turn to the Anchoring model was our unexpected result concerning the reflectance of the inducers: our darker (6\% reflectance) and the lighter (33\%) inducers rendered our targets lighter than the middle grey inducers (20\%). This effect was not expected and the only reason we introduced this variation in the inducers' reflectance was to change the ratio with the targets to test the Differential stimulation hypothesis (Steger, 1968). And to meet the desired conditions, we only ever used the surfaces that were light middle grey, or darker. Within the Anchoring theory (Gilchrist et al, 1999) it would be expected that in such a dark environment all of our targets should be seen as lighter, with a somewhat stronger effect for darker targets. This lighter appearance was obtained for 14 out of 18 data points, and the effect was stronger for the darker target stimuli (Graph 5 left, obtained measurements are further from the control stimuli presented with the dashed line). This latter effect was not a celling effect (the lightest target 
was estimated 1.7 on the log reflectance scale with 2.0 max). Although even the Anchoring model cannot fully explain the effect of the middle grey inducers this general lightness model was more successful in predicting obtained results than any other specialized hypothesis we have discussed.

In this study, we introduced depth to achieve several methodological gains. Most importantly, we have avoided the phenomenological difference produced by classically used displays. Furthermore, the same type of display and the same target were used to elicit both phenomena. It is interesting to demonstrate that in such conditions when each of the three manipulated factors (target reflectance, inducers' reflectance, and inducers' spatial frequency) had contributed separately, classical knowledge about the required display conditions fails. We can conclude that in the classical literature, the contribution to the effect was not made by a single factor but by the interaction of the factors. Once the interaction was cancelled, via our methodological control, the effects vanished. Within our experimental paradigm, we obtained an interesting and much simpler pattern of data assimilation was only obtained with increment, while contrast was only obtained with decrement inducers.

\section{Funding}

This research was supported by Ministry of Education and Science in the Republic of Serbia, Grants No. 179033 and III47020.

\section{Conflict of interest}

We have no conflicts of interest to disclose.

\section{Data availability statement}

Data used in this paper is available at: https://osf.io/qe239/.

\section{References}

Agostini, T., \& Galmonte, A. (1999). Spatial articulation affects

lightness. Perception \& psychophysics, 61(7), 1345-1355.

http://dx.doi.org/10.3758/bf03206185

Agostini, T., \& Galmonte, A. (2002). Perceptual organization overcomes the effects of local surround in determining simultaneous lightness 
contrast. Psychological science, 13(1), 89-93. http://dx.doi.org/10.1111/1467$\underline{9280.00417}$

Beck, J. (1966). Contrast and assimilation in lightness judgments. Perception \& Psychophysics, 1(10), 342-344. http://dx.doi.org/10.3758/bf03215800

Bressan, P. (2006). The place of white in a world of grays: A double-anchoring theory of lightness perception. Psychological Review, 113(3), 526-553. http://dx.doi.org/10.1037/0033-295x.113.3.526

Bressan, P., \& Actis-Grosso, R. (2006). Simultaneous lightness contrast on plain and articulated surrounds. Perception, 35(4), 445-452. http://dx.doi.org/10.1068/p5247

de Weert, C. M., \& Spillmann, L. (1994). Assimilation: Asymmetry between brightness and darkness? Vision Research, 35(10), 1413-1419. http://dx.doi.org/10.1016/0042-6989(95)98721-k

de Weert, C. M., \& van Kruysbergen, N. (1997). Assimilation: central and peripheral effects. Perception, 26(10), 1217-1224. http://dx.doi.org/10.1068/p261217

Economou, E., Zdravković, S., \& Gilchrist, A. (2015). Grouping factors and the reverse contrast illusion. Perception 44(12), 1383-1399. http://dx.doi.org/10.1177/0301006615607118

Festinger, L., Coren, S., \& Rivers, G. (1970). The Effect of Attention on Brightness Contrast and Assimilation. The American Journal of Psychology, 83(2), 189-207. http://dx.doi.org/10.2307/1421323

Gilchrist, A. L. (1980). When does perceived lightness depend on perceived spatial arrangement? Perception and Psychophysics, 28, 527-538. http://dx.doi.org/10.3758/bf03198821

Gilchrist, A. L., \& Annan Jr, V. (2002). Articulation effects in lightness: Historical background and theoretical implications. Perception, 31(2), 141-150. http://dx.doi.org/10.1068/p04sp

Gilchrist, A., Kossyfidis, C., Bonato, F., Agostini, T., Cataliotti, J., Li, X., ... \& Economou, E. (1999). An anchoring theory of lightness perception. Psychological review, 106(4), 795-834. http://dx.doi.org/10.1037/0033-295x.106.4.795

Helson, H. (1963). Studies of Anomalous Contrast and Assimilation. Journal of the Optical Society of America, 53(1), 179-184. http://dx.doi.org/10.1364/josa.53.000179 
Helson, H., \& Joy, V. L. (1962). Domains of lightness contrast and assimilation. Psychologische Beitrage, 6, 405-415.

Helson, H., \& Rholes, F. (1959). A Quantitative Study of Reversal of Classical Lightness-Contrast, The American Journal of Psychology, 72(4), 530-538. http://dx.doi.org/10.2307/1419494

Jameson, D., \& Hurvich, L. M. (1975). From contrast to assimilation: In art and in the eye. Leonardo, 125-131. http://dx.doi.org/10.2307/1572954

Katz D, (1935). The World of Colour. London: Kegan Paul, Trench, Trubner \& Co.

Logvinenko, A. D., Petrini, K., \& Maloney, L. T. (2008). A scaling analysis of the snake lightness illusion. Perception \& Psychophysics, 70(5), 828-840. http://dx.doi.org/10.3758/pp.70.5.828

Soranzo, A., Acaster, S., Taroyan, N., \& Reidy, J. (2020). Depth plane separation affects both lightness contrast and assimilation. Frontiers in Psychology, 11. http://dx.doi.org/10.3389/fpsyg.2020.02114

Soranzo, A., Galmonte, A., \& Agostini, T. (2010). Von Bezold Assimilation Effect Reverses in Stereoscopic Conditions. Perception, 39(5), 592-605. http://dx.doi.org/10.1068/p6462

Spehar, B., Gilchrist, A., \& Arend, L. (1995). The critical role of relative luminance relations in White's effect and grating induction. Vision research, 35(18), 2603-2614. https://doi.org/10.1016/0042-6989(95)00005-k

Steger, J. A. (1969). Visual Lightness Assimilation and Contrast as a Function of Differential Stimulation. The American Journal of Psychology, 82(1), 56-72. https://doi.org/10.2307/1420607

Todorović, D., \& Zdravković, S. (2014). The roles of image decomposition and edge curvature in the 'snake'lightness illusion. Vision research, 97, 1-15. https://doi.org/10.1016/j.visres.2014.01.015 


\title{
Kontrast i asimilacija svetline: testiranje hipoteza
}

\author{
Predrag Nedimovići (iD), Sunčica Zdravković (iD
}

1 Laboratorija za eksperimentalnu psihologiju, Odeljenje za psihologiju, Filozofski fakultet, Univerzitet u Beogradu, Srbija

2 Laboratorija za eksperimentalnu psihologiju, Odsek za psihologiju, Filozofski fakultet, Univerzitet u Novom Sadu, Srbija

\section{SAŽETAK}

Kontrast svetline je fenomen $u$ kome dve sive mete jednake luminanse izgledaju kao da imaju različitu svetlinu usled toga što meta koja je okružena crnom površinom izgleda svetlije od mete koja je okružena belom površinom. Asimilacija svetline je fenomen u kome siva meta koja je okružena crnom površinom izgleda tamnije od mete jednake luminanse koja je okružena belom pozadinom. Prethodne studije istakle su značaj određenih aspekata stimulacije koji utiču na pojavu jednog od ova dva fenomena: spacijalna frekvenca induktora, veličina i smer razlike u reflektansi mete i induktora. Osim toga, na osnovu prethodnih studija, moguće je formulisati tri precizne hipoteze koje predviđaju pojavu ova dva fenomena: spacijalna frekvenca, diferencijalna stimulacija i asimetrija asimilacije. $U$ ovom istraživanju, varirali smo reflektansu mete i induktora, kao i spacijalnu frekvencu induktora. Ova manipulacija omogućila nam je da testiramo uticaj ovih faktora, kao i da, na osnovu tri hipoteze imamo precizne predikcije za svaki stimulus. Naši rezultati su potvrdili uticaj testiranih faktora na svetlinu mete. Predložene hipoteze su loše predviđale dobijene podatke. Hipoteza diferencijalne stimulacije je tačno predvidela dobijen efekat za manje od pola stimulusa. Hipoteza spacijalne frekvence nije tačno predvidela veličine dobijenih efekata. Osim toga, najveći efekat asimilacije dobijen je sa induktorima niske spacijalne frekvence. Hipoteza asimetrije asimilacije nije predvidela ni jedan dobijen efekat..

Ključne reči: svetlina, kontrast, asimilacija, spacijalna frekvenca, hipoteza diferencijalne stimulacije 
